\title{
Retro aber nicht von Gestern
}

Früher war alles besser. Das stimmt natürlich nicht. Aber, dass viele Produkte aus vergangenen Tagen einen ganz eigenen Charme haben, ist sicher richtig. So haben klassische Sucherkameras auch heute noch viele Freunde. In Zeiten digitaler Fotografie will man aber auf die Vorzüge der modernen Technik nicht verzichten. Leica baut Kameras für solche Wünsche - allerdings zu Preisen, die selbst engagierte Hobbyfotografen schlucken lassen. Eine Alternative bietet Fuji mit der X-Serie. Die X-100S, Nachfolgerin der aufsehenerregenden X-100 ist eine Kamera im gehobenen aber noch bezahlbaren Preissegment für Fotografen, die eine kompakte Sucherkamera nutzen möchten, die eine sehr gute Bildqualität aufweist.

\section{Klassische Bedienung}

Ein auffälliges Merkmal der X-100S ist ihr Bedienkonzept, das besonders Fotografen gefallen dürfte, die an klassische Spiegelreflex- oder Sucherkameras gewöhnt sind. Drehschalter zum Einstellen der Modi und ein veritabler Blendenring am Objektiv sind für viele noch immer die intuitivste Art, eine Kamera zu bedienen.

\section{Besonderer Sensor}

Die X-100S verwendet einen sogenannten X-Trans-CMOS-IISensor im APS-C-Format (16,3 Megapixel Auflösung) in dessen Farbfilter die Pixel nach einem zufälligen Schema angeordnet sind. Dadurch kann auf den optischen Tiefpassfilter verzichtet werden. Dieser Filter verhindert in anderen Digitalkameras die Bildung von Moirés, allerdings auf Kosten der Auflösung. Beim X-Trans-CMOS-II-Muster nimmt der Sensor das Licht aus dem Objektiv ungefiltert auf, wodurch eine sehr hohe Auflösung erzielt wird. Die verbesserte Leistung des EXR-II-Prozessors, der in der X-100S verwendet wird, wirkt zudem Bildfehlern, wie Lichtsäumen und Beugungsunschärfe, entgegen.

Eine Schwäche des Vorgängermodells X-100 war die Geschwindigkeit, dies wurde bei der X-100S behoben. Der Einsatzbereich der Kamera erweitert sich dadurch auf Schnappschüsse oder etwa Sportaufnahmen. Wobei Letzteren durch die Festbrennweite Grenzen gesetzt sind. Wem Sportaufnahmen sehr wichtig sind, der wird wohl doch eher zu einer digitalen Spiegelreflex mit entsprechendem Tele greifen.

Als „Immer-dabei-Kamera“ mit hervorragender Bildqualität ist die X-100S jedoch eine gute Wahl. Der Listenpreis beträgt knapp 1.200 Euro - viel Geld, aber nicht zu viel.

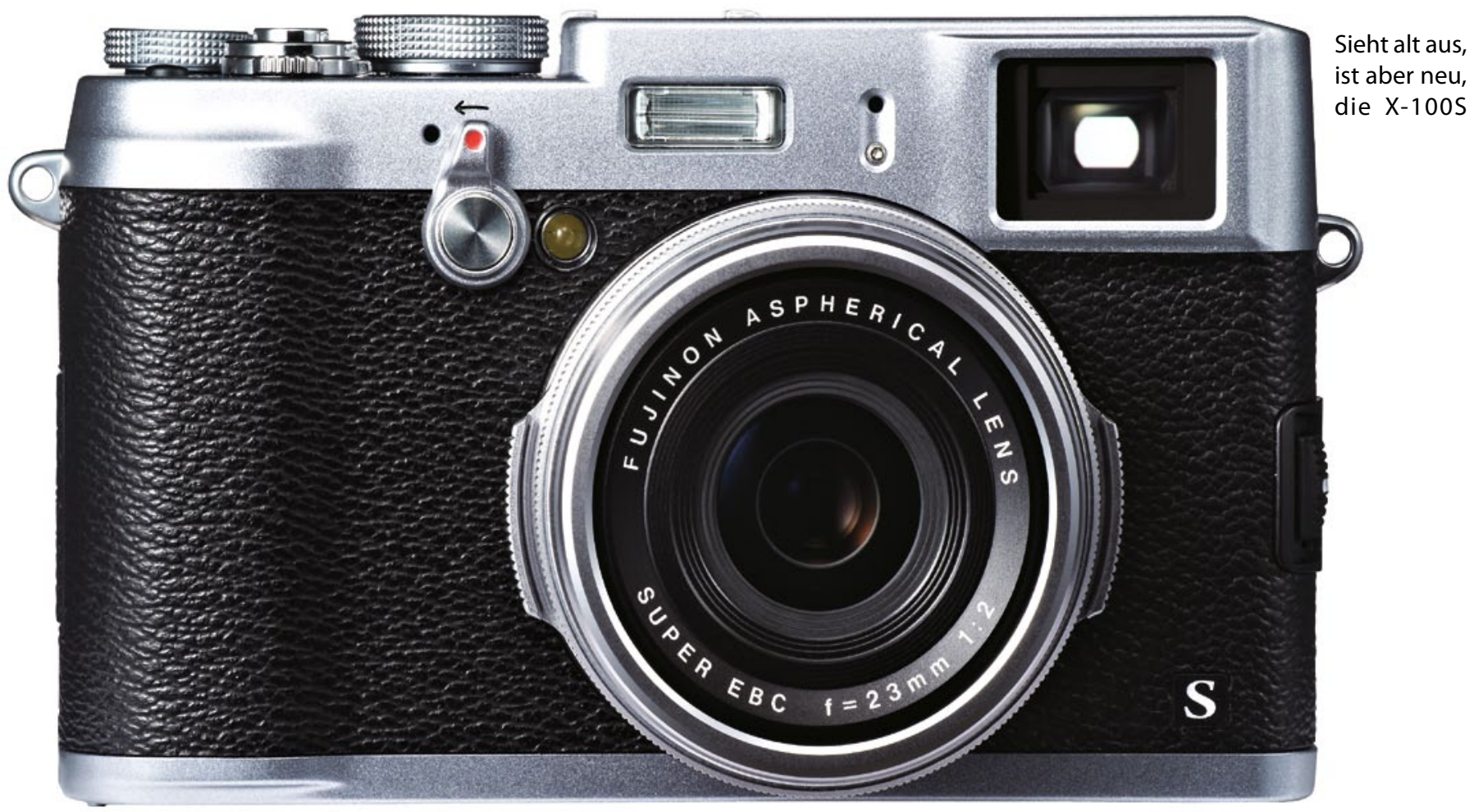

